\title{
SOME THOUGHTS ABOUT THE CONCEPTUAL / PROCEDURAL DISTINCTION IN TRANSLATION: A KEY-LOGGING AND EYE-TRACKING STUDY OF PROCESSING EFFORT ${ }^{1}$
}

\author{
Fábio Alves \\ Universidade Federal de Minas Gerais (Brazil) \\ fabio-alves@ufmg.br \\ José Luiz Gonçalves \\ Universidade Federal de Ouro Preto (Brazil) \\ zeluizvr@ichs.ufop.br \\ Karina S. Szpak \\ Universidade Federal de Minas Gerais (Brazil) \\ kszpak@ufmg.br
}

\begin{abstract}
This article builds on the conceptual / procedural distinction postulated by Relevance Theory to investigate processing effort in translation task execution. Drawing on relevance-theoretic assumptions, it assumes that instances related to procedural encodings will require more effortful processing not only in relation to the time spent on the task but also in terms of product indicators such as seconds per word and number of micro translation units per word. Drawing on key-logging and eye-tracking data, the article shows that there are statistically significant differences when conceptual and procedural encodings are analysed in selected areas of interest, with instances related to procedural encoding requiring more processing effort to be translated. The results are relevant for translation process research as they signal to where processing effort
\end{abstract}

1. Research funded by CNPq, the Brazilian Research Council (grant 307964/2011-6); and FAPEMIG, the Research Agency of the State of Minas Gerais (grants SHA/PPM-0049512 and SHA/PPM-00087-12). 
is predominantly located. Additionally, the discussion also contributes to validating experimentally some claims postulated by Relevance Theory.

\section{Resumen}

Este artículo se basa en la distinción entre codificaciones conceptuales y procedimentales postulada por la Teoría de la Relevancia para investigar el esfuerzo de procesamiento en tareas de traducción. Con base en esta teoría, se asume que los casos relacionados con codificaciones procedimentales requieren más esfuerzo de procesamiento no sólo en relación al tiempo empleado en la tarea, sino también en términos de indicadores de producto, tales como segundos por palabra y número de micro unidades de traducción por palabra. Utilizando datos de registro de teclado y ratón, así como datos de seguimiento ocular, el artículo muestra que existen diferencias estadísticamente significativas entre las codificaciones conceptuales y las procedimentales cuando se analizan áreas de interés seleccionadas. Los casos relacionados con la codificación procedimental requieren más esfuerzo de procesamiento para traducirlos. Los resultados son relevantes para la investigación del proceso de traducción, ya que indican dónde se concentra predominantemente el esfuerzo de procesamiento al traducir. Además, el debate contribuye a validar experimentalmente algunos principios postulados por la Teoría de la Relevancia.

Keywords: Translation process research. Relevance Theory. Conceptual / procedural distinction. Key logging. Eye tracking.

Palabras clave: Proceso de traducción. Teoría de la Relevancia. Codificación conceptual / procedimental. Registros de teclado y ratón (key logging). Seguimiento ocular (eye tracking).

Manuscript received on May 31, 2013 and accepted on September 30, 2013. 


\section{Introduction}

The use of eye tracking has gained impetus in translation process research lately. Jakobsen \& Jensen (2008), Pavlović \& Jensen (2009), Hvelplund (2011), Carl \& Kay (2011), Carl \& Dragsted (2012) and Alves, Gonçalves \& Szpak (2012), among others, have shown that eye fixations differ in areas of interest (AOIs, henceforth) found in source and/or target texts and, thus, suggest interesting implications in terms of reading/writing for translation. These authors assume that the allocation of cognitive resources in translation is essentially an information-processing task that can be assessed in real time. In conjunction, key-logging and eye-tracking data emerge as powerful indicators of processing effort in translation.

Research using key logging builds on the recursive nature of the writing process (Flower $\&$ Hayes 1981) and on the notion of cognitive rhythm (Schilperoord 1996), first applied to translation process research by Jakobsen (2002). Research using eye tracking draws on the works of Just \& Carpenter (1980) and Rayner (1998), among others, and rests on the overall assumption that eye-tracking data can be interpreted as correlates of on-going cognitive processing and, thus, offers a window into human information processing. Building on Just \& Carpenter's (1980) eye-mind assumption, authors in translation process research assume that eye fixations can be used to map instances of processing effort in source and/or target texts and account for cognitive traits inherent to human translation processes.

Jakobsen \& Jensen (2008) analyse reading for understanding, for translating, for sight translation, and for written translation to account for different reading modalities in translation. Measured in terms of eye fixation duration, their results suggest that translators allocate more processing effort to target text (TT) processing rather than to correlated instances in source texts (ST). This seems to indicate that TT processing requires more effort than ST processing. Pavlović \& Jensen's (2009) use eye-tracking data to analyse directionality in translation and compare gaze patterns of professional and novice translators. Their results are in line with Jakobsen \& Jensen (2008) and show that ST comprehension and TT production are two processes which differ in 
terms of processing effort. Hvelplund (2011) also points out that processing effort is stronger for novice than for professional translators during ST and TT processing. Hvelplund measures fixation duration and pupil dilation to show that professional translators engage in automatic processing more often and longer than novice translators do. Hvelplund also suggests that switching attention between different processing modes, such as reading and writing, is easier for professionals and demands more effort from novice translators. Carl $\&$ Kay (2011) also investigate shifts of attention in relation to the segment being processed and segments that lie ahead. They show that professional translators are capable of typing a translation while already reading ahead in the ST, whereas novice translators often resort to a sequential processing mode and can only carry out one activity at a time. Carl \& Dragsted (2012) investigate differences between copying and translation tasks. They point out that TT production problems, and not comprehension, seem to determine sequences of reading and writing patterns. Comparing copying and translation tasks, Carl \& Dragsted (2012) show that, whereas there is more sequential reading/writing processes in translation, parallel reading and writing activities are more predominant in copying tasks.

In the aforementioned works, translation has been studied in terms of the allocation of processing effort during task execution. However, as Alves, Pagano \& Silva (2009) show, a fine-grained linguistic analysis of translation problems may also shed light onto relevant aspects of cognitive processing in translation. Alves, Gonçalves \& Szpak (2012) and Alves \& Gonçalves (2013) use Relevance Theory (Sperber \& Wilson 1986/1995) to investigate processing effort in translation drawing on the concepts of conceptual (CE) and procedural encodings (PE). Alves \& Gonçalves (2013) report of a study of key-logged data of professional translators performing direct and inverse translation tasks, and they show that problems related to procedural encodings demand more processing effort to be translated. Alves, Gonçalves \& Szpak (2012) analyse eye-tracking data using a similar methodology to identify instances where processing effort is stronger. Their results are in line with Alves \& Gonçalves's (2013), with the number of eye fixations in their data suggesting that processing effort in translation is stronger in problems related to procedural encodings.

This article builds on the works of Alves, Gonçalves \& Szpak (2012) and Alves \& Gonçalves (2013) to propose an adaptation of the methodology used in those papers in two combined steps. First, we use key-logged data to analyse micro translation units (micro TUs, henceforth) located in selected AOIs, defined according to relevance-theoretic assumptions. Secondly, eye tracking 
is used to probe further into the data and analyse fixation counts and fixation duration in selected AOIs. We claim that this methodological approach can offer an alternative to carry out fine-grained linguistic analyses of key-logging and eye-tracking data in translation process research and contribute to corroborate some assumptions postulated by Relevance Theory.

\section{Theoretical underpinnings}

Relevance Theory (Sperber \& Wilson 1986/1995) has been applied to the study of processing effort in translation (Alves \& Gonçalves 2003, Alves 2007), mainly by using the relevance-theoretic concepts of conceptual and procedural encodings proposed by Blakemore (2002) in order to identify a relation between processing effort and cognitive effect.

In relevance-theoretic terms, the function of conceptual expressions (i.e., open lexical categories, such as nouns, adjectives and verbs) is to convey conceptual meaning which is propositionally extendable and contributes to expanding the inferential processing of an utterance, whereas the function of procedural expressions is to activate domain-specific cognitive procedures (i.e., morph-syntactic constraints in utterance processing) and contributes to constraining the inferential processing of these same utterances. Relevance Theory assumes that the conceptual-procedural distinction guides inferential processing. And since most content words also carry some procedural meaning (Wilson 2011), therefore, processing effort in translation tends to concentrate more on problems related to procedural than conceptual encodings.

In order to clarify the distinction between $\mathrm{CE}$ and PE, we borrow an example from Alves \& Gonçalves (2013), namely the title of one of the source texts used in their paper:

Coagulation activation and inflammation in sickle cell disease_associated pulmonary hypertension

In the example above, normal type fonts refer to items that exclusively convey conceptual encodings; underlined fonts refer to items that exclusively convey procedural encodings; and bold-face fonts refer to hybrid encodings related to items in which conceptual encodings have a procedural function. In the noun phrase "Coagulation activation and inflammation", for instance, it is quite transparent that there are three content words (coagulation; activation; inflammation) and a function word (and). However, besides being a content, referential word, in terms of the instructions it encodes, Coagulation also works as a modifier for other content words. Therefore, it is analysed as a case of hybrid encoding according to the theoretical framework adopted 
by Relevance Theory. It is also relevant to note that words and encodings have different roles in a relevance-theoretic account of inferential processing. Whereas content and function words are lexical items used in text production, encodings concern the type of instructions conveyed by such words, namely conceptual, procedural or hybrid instructions (Blakemore 2002, Wilson 2011).

The studies of Alves (2007) and Alves \& Gonçalves (2003) show there is a relation between processing effort and cognitive effect in translation and also that the conceptual-procedural distinction plays a role in such processes. Alves \& Gonçalves (2013) build on these previous relevance-theoretic findings and corroborate them by means of statistical analyses. Using key-logged data to map instances of conceptual and procedural encodings onto micro/ macro TUs (Alves \& Vale 2009, 2011), Alves \& Gonçalves (2013) show that problems related to procedural encodings demand more processing effort both in direct and inverse translation tasks.

According to Alves \& Vale (2011: 107), a micro TU is defined as "[...] the flow of continuous target text production-which may incorporate the continuous reading of source and target text segments-separated by pauses during the translation process as registered by key-logging and/or eye-tracking software. It can be correlated to a source text segment that attracts the translator's focus of attention at a given moment." The definition of the pause duration threshold between every two micro translation units will depend on the respective theoretical constraints. In this paper, we adopt the values suggested by Jakobsen (2005), i.e., 2.4 seconds as the minimum pause time limit, as explained on section 3.3 below. A macro TU, on the other hand, is "[...] defined as a collection of micro TUs that comprises all the interim text productions that follow the translator's focus on the same ST segment from the first tentative rendering to the final output that appears in the TT." Alves $\&$ Vale (2011) classify macro TUs with editing procedures taking place only in the drafting phase as $\mathrm{P} 1$. Those macro TUs that are produced once in the drafting phase and changed only in the revision phase are classified as P2. Finally, those macro TUs that undergo editing procedures both during drafting and revision are classified as P3. Alves \& Gonçalves (2013) have broadened Alves $\&$ Vale's (2011) taxonomy to include a P0 macro TU, corresponding to those micro TUs that do not undergo any editing at all. Such micro TUs are also considered macro TUs for annotation purposes. It is important to highlight here that we distinguish editing procedures from first rendering production: the former comprises some kind of addition, deletion, or modification performed 
on some initial production whereas the latter corresponds to the very first version of a given translation unit.

In their attempt to map problems related to conceptual and procedural encodings onto translation process data, Alves \& Gonçalves (2013) have also annotated more detailed editing procedures inside each macro TU to account for the level of linguistic complexity in an editing procedure. The results of Alves \& Gonçalves (2013) suggest that the allocation of cognitive resources in translation can be illustrated as $\mathrm{P} 0>\mathrm{P} 1>\mathrm{P} 3>\mathrm{P} 2$. Drawing on relevance-theoretic assumptions, the authors argue that subjects concentrate editing procedures within or very close to the respective initial micro TU and systematically attempt to reduce processing effort in order to optimise the resources in their cognitive environments. If they postpone the solution to a problem, or only fully realise this problem later on, the required processing effort needed to re-activate relevant information will be suboptimal in terms of cognitive processing economy. This is consistent with the relevance-theoretic framework, since additional processing effort diminishes the relevance of the cognitive effects, described by Alves \& Gonçalves (2013: 109) as effects that,

correspond to the changes taking place in the cognitive environment as a result of inferential processes (i.e., the pieces of information added, changed or even excluded); effort, in turn, is the amount of cognitive resources spent in those processes. None of them can be measured in terms of precise amounts-they can only be estimated and treated in comparative dimensions. Therefore, for any input to be considered more or less relevant, it will depend on the balance between these two factors (effects and effort).

Alves \& Gonçalves (2013) have also found that the total number of problems related to conceptual and procedural encodings is highest in $\mathrm{P} 1$, followed by P3. They assume that this can be interpreted in terms of allocation of processing effort to phases in the translation process, indicating where this effort is greater. In P1, subjects interrupt the cognitive flow to deal with more immediate processing problems. In P3, however, part of problem solving is accomplished in the end-revision phase. Their results point to prevalence of processing effort for procedural encodings in absolute terms, particularly in $\mathrm{P} 1$ and $\mathrm{P} 3$ where processing effort seems to be concentrated.

Along similar lines, Alves, Gonçalves \& Szpak (2012) have proposed a methodological approach to map eye movements onto macro TUs. The authors also show that the number of eye fixations is higher in problems related to procedural encodings than in problems related to conceptual encodings. An interesting question that emerges from the studies of Alves, Gonçalves \& Szpak (2012), with eye-tracking data, and Alves \& Gonçalves (2013), with key-logged data, is whether an analysis combining key logging and eye 
tracking would corroborate the results of the two previous studies. Drawing on Alves \& Gonçalves (2013) and Alves, Gonçalves \& Szpak (2012), in this paper we analyse both key-logged and eye-tracking data in an experiment which aims at investigating the performance of the same subjects who had participated in the two previous studies, now performing a new translation task, to probe once again into the conceptual/procedural distinction in translation. By doing this, we hope to put the results to the empirical-experimental test and also to validate experimentally some theoretical claims of Relevance Theory by applying them to translation process research.

\section{Methodology}

Eight Brazilian translators with at least five years of professional experience were asked to translate into Portuguese (L1) a source text in English (L2) about the physics of crumpling paper. The English ST has 186 words and was published in Scientific American, a science popularization magazine. Translators worked without time pressure, and were allowed to use the online dictionary Babylon as a resource for external support. Before starting to translate, subjects were instructed by a brief of the task with a detailed description at hand.

Data was collected using the triangulation paradigm in translation process research (Alves 2003). Keyboard and mouse actions were registered by means of Translog2006 whereas eye movements were recorded with a Tobii T60 eye tracker. Before data collection, subjects were asked to perform a copy test to serve as a baseline for typing speed and help them to familiarise themselves with the working conditions in the research setting. A QWERTY keyboard, familiar to all subjects, was used in the experiment. Eye calibration was performed according to the instructions provided in the Tobii T60 user's manual.

Building on Alves \& Gonçalves (2013) and Alves, Gonçalves \& Szpak (2012), we have refined the methodology to investigate the relevance-theoretic conceptual/procedural distinction in translation. We have thus correlated micro TUs registered in key-logged files to macro TUs observed in previously defined AOIs. The next subsections present the methodological steps taken to achieve that end.

\subsection{Analysis of source text from a relevance-theoretic perspective}

The ST used in the experiment, displayed in figure 1, was divided into 12 AOIs, six in each paragraph. The eight AOIs selected for the study are AOI_1 to AOI_7 and AOI_10. In relevance-theoretic terms, the selected AOIs contain instances of conceptual and procedural encodings, highlighted in italics, 
which we considered to be potentially effortful for purposes of translation task execution.

AOI_1 Crumpling a sheet of paper seems simple and doesn't require much effort, but explaining the crumpled ball's behavior is another matter entirely.

AOI_2 Once a paper ball is scrunched, it is more than 75 percent air.

AOI_3 Yet it displays surprising strength and resists further compression,

AOI_4 a fact that has confounded physicists.

AOI_5 A report in Physical Review Letters, though, describes one aspect of the behavior of crumpled sheets:

AOI_6 changes in their size in relation to the force they withstand.

AOI_7 A crushed thin sheet is essentially a mass of conical points connected by curved ridges, which store energy.

AOI_8 In the event of further compression of the sheet these ridges collapse and smaller ones form, increasing the amount of stored energy within the wad.

AOI_9 Scientists at the University of Chicago modeled the relation between compression force and ball size.

AOI_10 The researchers crumpled a sheet of thin aluminized Mylar

AOI_11 and then placed it inside a cylinder equipped with a piston to crush the sheet.

AOI_12 Instead of collapsing to a final fixed size, the height of the crushed ball continued to decrease, even three weeks after the researchers had applied the weight.

Figure 1. AOIs in Source Text (selections in italics).

The ST has two paragraphs with somewhat different structures. The first paragraph has 77 words (405 characters) while the second paragraph is longer, containing 109 words (551 characters). The first paragraph is structured in six sentences (AOIs 1 to 6 ) that create a cohesive chain which attempts to convey the cause/effect relation for the problem described in the article, namely the physics of crumpling paper. The connectives but, once, yet, and though, together with the phrase a fact that and the colon followed by changes in their size in relation to, build a sequence of causal relations that guides readers into understanding the physics of crumpling paper. According to relevance-theoretic assumptions, this chain of procedural encodings help translators in their inferential processing in order to generate cognitive effects in their TT output. The second paragraph, in turn, explains what is a crushed thin sheet and 
describes the procedures that account for the results obtained by scientists at the University of Chicago. This second paragraph consists of six sentences (AOIs 7 to 12) which are independent from one another in structural terms. However, two noun groups, "curved ridges" and "a sheet of thin aluminized Mylar", stand out as terminological items that may pose problems to translators. These potential translation problems were selected as AOIs containing conceptual encodings. Therefore, for the purposes of the present study, AIOs 1 to 7 and AOI_10 constitute the focus of the analysis whereas AOIs $8,9,11$ and 12 were grouped together in one block of other areas of interest (O/AOIs) when statistical analyses were carried out.

\subsection{Hypotheses}

Being $18 \%$ longer than the first paragraph, one would expect the second paragraph to require more time to be translated. However, when examining the conceptual and procedural encodings in the ST, one notices that the first paragraph conveys six potential procedural encoding-related problems, while the second paragraph, although longer, relates more specifically to two instances of potentially problematic conceptual encodings, conveyed by the noun phrases "curved ridges" and "a thin sheet of aluminized Mylar." Needless to say that we are aware of the procedural encodings present in the second paragraph. Nevertheless, we decided to focus our analysis on the conceptual encodings to see how their processing differed from those related to encodings found in the first paragraph.

In accordance with relevance-theoretic assumptions and drawing on the results of Alves \& Gonçalves (2013), one could hypothesise that the higher number of procedural encodings in the first paragraph requires more processing effort to be translated. We measured this not only in terms of the time allocated to text production as registered by key logging, but also depending on the number of micro TUs in the specified AOIs. Hypothesis one thus reads:

In comparison to total task time, the first paragraph, although shorter, will take longer to translate. Processing effort will be higher not only in terms of time but also in respect to the number of micro TUs allocated to instances related to procedural encodings.

We also used eye-tracking data to assess relevance-theoretic assumptions related to a second hypothesis. One would assume that instances of conceptual encodings might also take some reasonable amount of time to be translated. Nevertheless, processing effort would be of a different nature. Whereas processing effort in issues related to procedural encodings would be distributed in the first paragraph with a high number of more complex, 
recursive movements along the process, the conceptual encodings selected in the second paragraph would show a localised type of processing, with substantial time allocated to sources of external support such as dictionary look-ups. Hypothesis two thus reads:

Processing effort will be higher in instances related to procedural encodings as shown by a higher number of micro TUs, pointing to a more complex, and distributed type of cognitive processing. The number of micro TUs allocated to instances related to conceptual encodings will be lower and point to a more localised type of processing.

\subsection{Data treatment}

Based on Alves \& Gonçalves (2013), the log files of the eight professional translators were segmented into micro TUs separated by a pause value of 2.4 seconds, a value deemed to be representative of segmentation patterns among more expert translators (Jakobsen 2005). The Translog linear representations show idiosyncratic patterns across the sample. The number of micro TUs ranges from a maximum of 108 to a minimum of 26 for the translation of the same ST. That difference in numbers notwithstanding, it is possible to assess the data in order to show how much processing effort each translator allocated to the eight selected AOIs selected and then compare the data among subjects. This procedure also allows us to indicate how much processing effort is located within, or falls outside the scope of, the selected AOIs.

A second step consists in the analysis of heat maps indicating instances in the translation process where processing effort is higher, through fixation counts and duration. A heat map indicates points where eye movements concentrate in terms of number of eye fixations and their duration. When using colours, there is a gradient that goes from green (indicating a smaller number of eye fixations), through yellow and orange, to red (indicating a higher number of, and longer, eye fixations). In this paper, those areas with higher or lower number of, and shorter, fixations can be recognised in shades of grey. The white areas (yellow, when coloured) point to a number and duration of fixations above average while the dark grey areas (orange or red, when coloured) indicate a high number of, and longer, fixations. The light grey areas (green, when coloured) depict a low number of, and shorter, fixations. Figure 2 displays an example of a heat map for one of the eight professional translators, with eye fixation being determined by gaze lasting $250 \mathrm{~ms}$ or longer (Rayner \& Sereno 1994). 


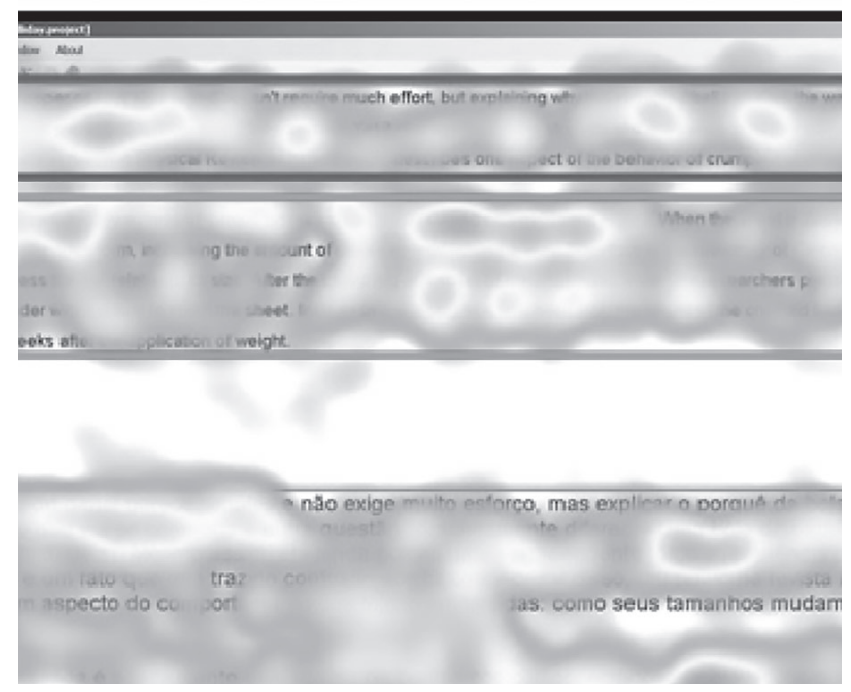

Figure 2. Example of a heat map with its AOIs.

Heat maps provided by Tobii Studio software show both fixation count and fixation duration from a graphic perspective according to visual activity. Such activities are easily identified in both ST and TT areas, respectively the upper and lower areas in each individual heat map. Instances with higher fixation counts/duration probably correspond to translation problems which require more time and effort to be processed. Thus, they are deemed to be cognitively relevant in terms of processing effort. In the heat map displayed in figure 2 , the selected AOIs in the first and second paragraphs of the ST indicate points in the process where eye fixations were longer. Empirically speaking, they suggest that a selection made on the basis of relevance-theoretic assumptions is feasible. Individual heat maps for the eight subjects illustrating the distribution of effort in terms of fixation duration, in appendix 1.

\section{Analysis and discussion}

Our analysis builds on the results of Alves \& Gonçalves (2013) for key-logged data and Alves, Gonçalves \& Szpak (2012) for eye-tracking data. We compare the number of micro TUs with the number and duration of eye fixations for eight selected AOIs. As these AOIs are spread throughout the ST with procedural encoding-related problems concentrated on the first paragraph and two instances of conceptual encoding-related problems in the second paragraph, 
an analysis of the time spent on each paragraph can provide insights into the amount of processing effort in different parts of the ST. Anderson-Darling normality tests confirm that parametric t-tests are adequate for the data set under scrutiny (see appendix 2). Table 1 displays information related to time spent on the task.

\begin{tabular}{|l|r|r|r|r|r|r|r|r|r|c|c|}
\hline Subject & Jane & Cicy & Adam & Jim & Will & Mona & Tess & Rui & Means & $\begin{array}{c}\mathbf{N}^{\text {o }} \text { of } \\
\text { words }\end{array}$ & $\begin{array}{c}\text { Secs/ } \\
\text { Word }\end{array}$ \\
\hline $1^{\text {st }} \mathrm{P}$. & 703 & 421 & 1059 & 270 & 627 & 224 & 529 & 543 & 547.0 & 77 & 7.1 \\
\hline $2^{\text {nd }} \mathrm{P}$ & 814 & 545 & 692 & 411 & 1077 & 385 & 700 & 494 & 639.8 & 109 & 5.9 \\
\hline $\mathbf{1}^{\text {st }}+2^{\text {nd }}$ P. & 1517 & 966 & 1751 & 681 & 1704 & 609 & 1229 & 1037 & 1186.8 & 186 & 6.4 \\
\hline
\end{tabular}

$1^{\text {st }} \mathrm{P}$ - Normality test Anderson-Darling (0.256) p-value (0.616)

$2^{\text {nd }} \mathrm{P}-$ Normality test anderson-Darling $(0.242) \mathrm{p}$-value $(0.557)$

Table 1. Time spent on each paragraph [P.] (in seconds) and translation effort rate (secs. per word).

Table 1 shows task duration both in terms of the total time spent by each of the eight translators as compared to the time spent on the translation of each paragraph. The figures in table 1 indicate a mean total task time of 1.187 seconds. On average, $46.2 \%$ of the total time was allocated to the first paragraph, while $53.8 \%$ of the total time was spent in the translation of the second paragraph, a difference of $7.6 \%$ on the mean total time spent on the translation of the second paragraph. However, taking into account that, in number of words, the second paragraph is $18 \%$ longer than the first paragraph, there is a negative difference between the relative size of the ST and the relative time spent on the translation of each paragraph. This suggests that the first paragraph requires relatively more processing effort to be translated. Among the eight translators, six of them have individual numbers very close to the means. Only two translators, Adam and Rui, have diverging performance patterns. They spend relatively more time on the translation of the first paragraph. On average, translators require 547 seconds to translate the 77 words in the first paragraph, i.e. 7.1 seconds per word. On the other hand, they need 640 seconds to translate the 109 words of the second paragraph, working at a rate of 5.9 seconds per word. These results suggest that the first paragraph requires relatively more time to be translated and thus corroborate the initial assumption that procedural encodings demand more processing effort in translation. 
As described in section 3, micro TUs were mapped onto eight relevant areas of interest (AOIs) in the ST. First, they were mapped onto key-logged data and, secondly, onto eye-tracking data. Table 2 presents the micro TUs processed by each of the eight translators. It shows the total number of micro TUs as well as the numbers of micro TUs for each area of interest (AOI) and also includes the number of micro TUs that fall outside the selected AOIs (O/ AOI), including AOI_8, AOI_9, AOI_11 and AOI_12 (see figure 1).

When contrasting the results for $\mathrm{P}$ types of macro TUs with those obtained by Alves \& Gonçalves (2013), the total number of problems related to conceptual and procedural encodings is highest in P1. However, instead of being followed by P3, in our data these problems are related to P2 macro TUs. Nevertheless, these results can also be interpreted in terms of allocation of processing effort to phases in the translation process, indicating that in $\mathrm{P} 1$ subjects interrupt the cognitive flow to deal with more immediate processing problems, whereas in $\mathrm{P} 2$ or $\mathrm{P} 3$ problem solving is postponed to or concluded in the end-revision phase.

The differences between procedural encodings (PE) and conceptual encodings (CE) in table 2 is statistically significant, p-value (0.001), pointing

\begin{tabular}{lccrcccccccc}
\hline Subject & Jane & Cicy & \multicolumn{1}{c}{ Adam } & Jim & Will & Mona & Tess & Rui & Means & $\begin{array}{c}\text { Overall } \\
\text { means }\end{array}$ & $\begin{array}{c}\text { Pondered } \\
\text { Means* }\end{array}$ \\
\hline AOI_1 & $3(\mathrm{P} 1)$ & $4(\mathrm{P} 1)$ & $8(\mathrm{P} 1)$ & $1(\mathrm{P} 1)$ & $4(\mathrm{P} 2)$ & $1(\mathrm{P} 1)$ & $8(\mathrm{P} 2)$ & $7(\mathrm{P} 1)$ & 4.50 & & \\
AOI_2 & $7(\mathrm{P} 1)$ & $3(\mathrm{P} 1)$ & $10(\mathrm{P} 1)$ & $5(\mathrm{P} 1)$ & $2(\mathrm{P} 1)$ & $1(\mathrm{P} 1)$ & $2(\mathrm{P} 2)$ & $9(\mathrm{P} 3)$ & 4.88 & & \\
AOI_3 & $4(\mathrm{P} 1)$ & $5(\mathrm{P} 2)$ & $17(\mathrm{P} 1)$ & $3(\mathrm{P} 1)$ & $3(\mathrm{P} 2)$ & $2(\mathrm{P} 1)$ & $4(\mathrm{P} 1)$ & $3(\mathrm{P} 1)$ & 5.13 & 4.42 & 0.06 \\
AOI_4 & $6(\mathrm{P} 1)$ & $2(\mathrm{P} 1)$ & $15(\mathrm{P} 3)$ & $1(\mathrm{P} 0)$ & $2(\mathrm{P} 2)$ & $1(\mathrm{P} 0)$ & $2(\mathrm{P} 1)$ & $2(\mathrm{P} 2)$ & 3.88 & $(\mathrm{PE})$ & \\
AOI_5 & $6(\mathrm{P} 3)$ & $7(\mathrm{P} 1)$ & $9(\mathrm{P} 2)$ & $3(\mathrm{P} 1)$ & $5(\mathrm{P} 2)$ & $2(\mathrm{P} 1)$ & $3(\mathrm{P} 2)$ & $3(\mathrm{P} 1)$ & 4.75 & & \\
AOI_6 & $5(\mathrm{P} 1)$ & $5(\mathrm{P} 1)$ & $4(\mathrm{P} 1)$ & $2(\mathrm{P} 1)$ & $5(\mathrm{P} 2)$ & $2(\mathrm{P} 1)$ & $2(\mathrm{P} 1)$ & $2(\mathrm{P} 2)$ & 3.38 & & \\
AOI_7 & $6(\mathrm{P} 1)$ & $3(\mathrm{P} 1)$ & $7(\mathrm{P} 1)$ & $3(\mathrm{P} 2)$ & $3(\mathrm{P} 1)$ & $3(\mathrm{P} 2)$ & $4(\mathrm{P} 1)$ & $3(\mathrm{P} 1)$ & 4.00 & 3.19 & 0.12 \\
AOI_10 & $4(\mathrm{P} 1)$ & $3(\mathrm{P} 1)$ & $4(\mathrm{P} 1)$ & $1(\mathrm{P} 0)$ & $3(\mathrm{P} 1)$ & $2(\mathrm{P} 3)$ & $1(\mathrm{P} 0)$ & $1(\mathrm{P} 1)$ & 2.38 & $(\mathrm{CE})$ & \\
\hline O/AOIs & 41 & 25 & 34 & 14 & 65 & 12 & 37 & 31 & 32.38 & & \\
Total & 82 & 57 & 108 & 33 & 92 & 26 & 63 & 61 & 65.25 & & \\
\hline
\end{tabular}

*micro translation units per word

Normality Test Anderson-Darling for PE (procedural encodings) = AOI_1 to AOI_6 (0.686) p-value (0.045)

Normality Test Anderson-Darling for CE (conceptual encodings) = AOI_7 and AOI_10

(0.706) p-value (0.040)

Difference between PE and CE in micro TUs - Wilcoxon Test (62) p-value $(0.001)=$ significant

Difference between PE and CE in micro TUs per words - Wilcoxon Test (60) p-value $(0.003)=$ significant

Table 2. Number (and type) of micro units (absolute and mean values) in selected AOIs. 
to a higher number of micro TUs in PE-related AOIs than in CE-related ones. When we divide the number of micro TUs by the respective number of words in each AOI, the difference between PE and CE is statistically significant: the mean number of micro TUs per word is significantly higher for CE (0.12) than PE (0.06). This means, conversely, that the number of words per micro TU is significantly higher for PE than CE (p-value 0.003). Together with the results in table 1 , the data shows a longer mean time for processing words related to $\mathrm{PE}$ than $\mathrm{CE}$. On average, in PE-related AOIs words take longer (and require more effort) to be processed than in CE; in PE-related micro TUs, on average, there are more words; in PE-related AOIs, on average, there are more micro TUs - what leads to the conclusion that time/effort for PE-related problem solving is significantly higher than for CE.

Combining the results of tables 1 and 2, table 3 shows the amount of time (seconds) spent in each micro TU (Secs/MTU), and the division of this result by the number of words in each paragraph (Secs/MTU/Word); a rate we may consider another possible measure of processing effort in translation. Anderson-Darling normality tests confirm that parametric t-tests are adequate for the data set under scrutiny.

\begin{tabular}{|l|c|c|c|c|c|c|c|c|c|c|c|}
\hline Subject & Jane & Cicy & Adam & Jim & Will & Mona & Tess & Rui & Means & $\begin{array}{c}\mathbf{N}^{\text {o }} \text { of } \\
\text { words }\end{array}$ & $\begin{array}{c}\text { Secs/ } \\
\text { MTU/ } \\
\text { Word }\end{array}$ \\
\hline $1^{\text {st }} P$. & 22.7 & 16.2 & 16.8 & 18.0 & 69.6 & 10.6 & 25.2 & 20.8 & 25.0 & 77 & 0.32 \\
\hline $2^{\text {nd }} P$. & 15.9 & 17.6 & 15.4 & 22.8 & 63.3 & 5.4 & 16.6 & 14.1 & 21.4 & 109 & 0.20 \\
\hline $1^{\text {st }}+2^{\text {ndd }} P$. & 38.6 & 33.7 & 32.2 & 40.8 & 133.0 & 16.0 & 41.8 & 34.9 & 46.4 & 186 & 0.25 \\
\hline
\end{tabular}

$1^{\text {st }} \mathrm{P}$ - Normality Test Anderson-Darling (0.226) p-value (0.616)

$2^{\text {nd }}$ P- Normality Test Anderson-Darling (0.275) p-value (0.557)

Paired T-tests contrasting 1st and 2nd paragraph: seconds per MTU; Pondered Effort rates, $\mathrm{p}<0.01$ (significant)

Pearson's correlation coefficient correlating 1st and 2nd paragraph: seconds per MTU;

Weighted Effort rates, $\mathrm{r}=0.97$ (very strong)

Table 3. Time spent on each micro translation unit (secs/MTU) and weighted translation effort rate (secs/MTU/word).

Weighted effort rates contrasting the first and second paragraphs point to a significant difference in the number of words processed in each paragraph in relation to the number of micro TUs and the time spent on the task. The Pearson's correlation coefficient correlating the two paragraphs is also very strong, which reinforces the consistency of the difference between them and confirms that subjects spend more time and make more effort per micro TU in the first 
paragraph. Thus, table 3 confirms the tendencies observed in tables 1 and 2 , suggesting an interesting relation between the time spent on the task, the number of micro TUs, and the total number of words in each paragraph. With an average value of 0.32 second per micro TU/word in the first paragraph against 0.20 second per micro TU/word in the second paragraph, the results on table 3 , as weighted effort rates, confirm that PE requires more processing effort than CE for key-logged data. In short, these results demonstrate that each word and each micro TU in the first paragraph require more time to be processed when compared to each word and the micro TUs in the second paragraph, thus corroborating our first hypothesis. And, since PE-related problems are mainly located in the first paragraph, while CE ones appear in the second paragraph, an analysis of eye-tracking data for each paragraph could provide us with further insights into processing effort in translation related to the relevance-theoretic conceptual/procedural distinction.

In order to assess that, we analysed eye fixations in the selected AOIs. A major methodological problem in the analysis of CE and PE would be the impact of external support searches in the complete data set. During task execution, subjects often deviate their gaze from the computer screen or open other windows to look up dictionary entries and/or perform web searches. These actions are an integral part of the translation process and must be taken into consideration. To be more precise about the impact of external support searches on online processing, scenes were created separately for instances of internal and external support which occur predominantly for AOI_7 and AOI_10. Eye-tracking data related to external support searches, i.e., online dictionary look-ups, was then added to eye-tracking data related to internal support searches, i.e., when subjects lean only on their memory and inferences.

Table 4 shows fixation counts in both ST and TT areas. The average number of eye fixations is higher for AOIs 1 to 6, corresponding to instances of PE, and contrasts them to the fixation counts in AOI_7 and AOI_10. Wilcoxon Test contrasting PE and CE show a p-value of 0.0001 , which is statistically highly significant. As far as the conceptual/procedural distinction is concerned, the higher number of eye fixations in instances related to PE confirms the analysis of key-logged data and suggests that AOIs 1 to 6 demand more processing effort to be translated, thus corroborating relevance-theoretic assumptions related to the conceptual / procedural distinction.

Another interesting aspect is the number of fixation counts in ST and TT areas. The data suggests that there are more variations in the first paragraph, with eye movements going back and forth from ST and TT as well as 
encompassing longer stretches of text. The lower fixation counts for AOIs 7 and AOI_10, where instances of CE appear, could be due to the fact that eye fixations fell predominantly on the two noun groups and did not extend to other stretches of text. On average, fixation counts are higher on TT areas, a result that corroborates previous translation process studies (Jakobsen $\&$ Jensen 2008, Pavlović \& Jensen 2009, Hvelplund 2011, Carl \& Kay 2011, Carl \& Dragsted 2012 and Alves, Gonçalves \& Szpak 2012).

Next we analysed fixation duration for the selected AOIs. Table 5 shows fixation duration in both ST and TT areas. Wilcoxon Test contrasting PE and CE show a p-value of 0.003 , which is statistically significant. As far as the conceptual/procedural distinction is concerned, an analysis of eye fixation duration in instances of PE-related problems confirms the analysis of keylogged data and suggests that AOIs 1 to 6 demand more processing effort to be translated, thus corroborating relevance-theoretic assumptions related to the conceptual/procedural distinction.

\begin{tabular}{|c|c|c|c|c|c|c|c|c|c|c|c|c|c|c|c|c|c|c|c|c|}
\hline \multirow[t]{2}{*}{ Subject } & \multicolumn{2}{|c|}{ Jane } & \multicolumn{2}{|c|}{ Cicy } & \multicolumn{2}{|c|}{ Adam } & \multicolumn{2}{|c|}{ Jim } & \multicolumn{2}{|c|}{ Will } & \multicolumn{2}{|c|}{ Mona } & \multicolumn{2}{|c|}{ Tess } & \multicolumn{2}{|c|}{ Rui } & \multicolumn{2}{|c|}{ Means } & \multirow{2}{*}{$\begin{array}{c}\text { Means } \\
\text { ST+TT }\end{array}$} & \multirow{2}{*}{$\begin{array}{c}\text { Overal } \\
\text { means }\end{array}$} \\
\hline & ST & $\mathrm{TT}$ & ST & TT & ST & TT & ST & TT & ST & TT & ST & TT & ST & TT & ST & TT & ST & TT & & \\
\hline AOI 1 & 46 & 52 & 95 & 35 & 216 & 121 & 69 & 29 & 106 & 68 & 44 & 27 & 101 & 94 & 32 & 29 & 88.63 & 56.88 & 72.75 & \\
\hline AOI_2 & 19 & 52 & 37 & 44 & 144 & 227 & 34 & 29 & 20 & 13 & 14 & 15 & 48 & 89 & 25 & 68 & 42.63 & 67.13 & 54.88 & \\
\hline AOI_3 & 102 & 34 & 99 & 59 & 124 & 203 & 51 & 27 & 65 & 143 & 26 & 24 & 53 & 39 & 20 & 6 & 67.50 & 66.88 & 67.19 & \\
\hline AOI 4 & 19 & 36 & 14 & 11 & 60 & 338 & 17 & 17 & 56 & 56 & 10 & 4 & 19 & 16 & 18 & 10 & 26.63 & 61.00 & 43.81 & \\
\hline AOI_5 & 178 & 109 & 77 & 37 & 81 & 281 & 45 & 32 & 95 & 58 & 28 & 14 & 55 & 48 & 38 & 17 & 74.63 & 74.50 & 74.56 & \\
\hline AOI_6 & 25 & 29 & 33 & 47 & 28 & 112 & 29 & 13 & 83 & 205 & 22 & 25 & 28 & 26 & 20 & 14 & 33.50 & 58.88 & 46.19 & \\
\hline AOI_7 & 36 & 50 & 58 & 37 & 49 & 70 & 0 & 65 & 28 & 20 & 41 & 78 & 34 & 14 & 22 & 7 & 33.50 & 42.63 & 40.60 & 31.13 \\
\hline AOI_10 & 43 & 21 & 50 & 34 & 18 & 41 & 20 & 8 & 14 & 17 & 35 & 19 & 8 & 12 & 7 & 9 & 24.38 & 20.13 & 22.25 & \\
\hline $\mathrm{O} / \mathrm{AOIs}$ & 669 & 594 & 428 & 465 & 631 & 1005 & 386 & 310 & 619 & 1780 & 341 & 439 & 708 & 803 & 491 & 425 & 534.13 & 727.63 & 630.88 & \\
\hline Total & 1137 & 977 & 891 & 769 & 1351 & 2398 & 651 & $\mathbf{5 3 0}$ & 1086 & 2360 & 561 & 645 & 1054 & 1141 & 673 & 585 & 925.50 & 1175.63 & 1050.56 & \\
\hline
\end{tabular}

Normality Test Anderson-Darling for PE = AOI_1 to AOI_6 (0.690) p-value (0.044)

Normality Test Anderson-Darling for CE = AOI_7 and AOI_10 (0.639) p-value (0.060)

Fixation counts for PE and CE - Wilcoxon Test (64) p-value $(0.0001)=$ highly significant

Table 4. Fixation count in selected AOIs and in complete ST/TT (absolute and mean values).

Data on table 5 reinforces the argument that instances of conceptual encodings are processed in a localised fashion and do not extend to other stretches of text. Fixation duration is, on average, lower for AOI_7 and AOI_10. They take long to translate, mostly due to the need of external support, whose fixation time is included in the O/AOI measures. Time, however, as argued by Alves \& Gonçalves (2013), is not the only and most important feature when analysing processing effort in translation. Recursive movements seem to be equally or even more important. AOIs 1 to 6 seem to confirm this. On average, they show longer fixation durations, probably indicating recursive 
eye movements, going back and forth from ST and TT as well as encompassing longer stretches of text. Results suggest that instances of procedural encodings not only demand a higher number of fixations but also that these fixations are longer.

\begin{tabular}{|c|c|c|c|c|c|c|c|c|c|c|c|c|c|c|c|c|c|c|c|c|}
\hline \multirow[t]{2}{*}{ Subject } & \multicolumn{2}{|c|}{ Jane } & \multicolumn{2}{|c|}{ Cicy } & \multicolumn{2}{|c|}{ Adam } & \multicolumn{2}{|c|}{ Jim } & \multicolumn{2}{|c|}{ Will } & \multicolumn{2}{|c|}{ Mona } & \multicolumn{2}{|c|}{ Tess } & \multicolumn{2}{|c|}{ Rui } & \multicolumn{2}{|c|}{ Means } & \multirow{2}{*}{$\begin{array}{l}\text { Means } \\
\text { ST+TT }\end{array}$} & \multirow{2}{*}{$\begin{array}{l}\text { Overall } \\
\text { Means }\end{array}$} \\
\hline & ST & TT & $\mathbf{s T}$ & TT & ST & TT & ST & $\mathrm{TT}$ & ST & TT & ST & TT & ST & TT & ST & TT & $\mathbf{s T}$ & TT & & \\
\hline AOI_1 & 13.6 & 17.0 & 32.2 & 21.1 & 82.1 & 34.5 & 18.5 & 28.2 & 34.5 & 42.2 & 11.8 & 9.7 & 35.4 & 49.3 & 7.5 & 10.8 & 29,44 & 26,59 & 28,02 & \\
\hline AOI_2 & 0.1 & 20.1 & 11.0 & 19.7 & 42.5 & 91.9 & 11.4 & 21.5 & 7.9 & 9.4 & 3.1 & 4.2 & 14.4 & 40.2 & 0.5 & 31.4 & 12,87 & 29,80 & 21,33 & \\
\hline $\mathrm{AOI}_{-} 3$ & 34.1 & 10.1 & 39.7 & 32.0 & 40.6 & 74.3 & 18.8 & 20.0 & 23.7 & 74.2 & 6.1 & 12.2 & 18.9 & 26.2 & 5.1 & 2.5 & 23,36 & 31,45 & 27,40 & \\
\hline $\mathrm{AOI}_{4}$ & 8.2 & 12.9 & 4.6 & 4.9 & 18.1 & 120.7 & 4.6 & 12.0 & 18.5 & 28.5 & 1.7 & 1.3 & 4.6 & 8.5 & 4.4 & 7.8 & 8,07 & 24,58 & 16,33 & $\begin{array}{l}22.98 \\
\text { (PE) }\end{array}$ \\
\hline $\mathrm{AOI} 5$ & 53.8 & 41.7 & 25.0 & 19.6 & 22.3 & 109.4 & 22.6 & 21.8 & 33.2 & 27.9 & 6.1 & 4.6 & 15.2 & 28.6 & 10.0 & 4.6 & 23,51 & 32,27 & 27,89 & \\
\hline AOI_ 6 & 9.7 & 10.7 & 9.5 & 18.5 & 7.6 & 41.4 & 8.7 & 10.4 & 25.5 & 79.6 & 5.7 & 7.4 & 8.4 & 15.1 & 4.8 & 7.3 & 9,97 & 23,80 & 16,88 & \\
\hline A & 1 & 17 & 31.7 & 16 & 1 & 2 & 0 & 28 & 13.5 & 10.3 & 11.2 & 22 & 13.0 & 6.2 & 6.7 & & 12 & 35 & 15 & \\
\hline AOI_10 & 14.0 & 7.5 & 19.5 & 18.7 & 5.7 & 15.0 & 6.4 & 5.5 & 5.2 & 11.3 & 10.4 & 8.2 & 2.2 & 6.6 & 2.9 & 5.1 & 8,30 & 9,76 & 9,03 & E) \\
\hline O/AOIS & 230.3 & 184.5 & 150.1 & 209.2 & 168.4 & 354.8 & 147.0 & 154.3 & 208.0 & 715.0 & 83.8 & 131.2 & 220.0 & 335.1 & 154.4 & 129.1 & 170,24 & 276,63 & 223,44 & \\
\hline Total & 381.0 & 21.9 & 323.4 & 360.5 & 404.9 & 864.8 & 238.1 & 302.5 & 370.0 & 998.3 & 139.8 & 201.6 & 332.0 & 515.7 & 202.2 & 200.5 & 298,90 & 470,71 & 384,81 & \\
\hline
\end{tabular}

Normality Test Anderson-Darling for PE = AOI_1 to AOI_6 (1.15) p-value (0.004)

Normality Test Anderson-Darling for CE = AOI_7 and AOI_10 (0.213) p-value (0.825)

Wilcoxon Test contrasting PE and CE (60) p-value (0.003) = significant

Table 5. Fixation duration in selected AOIs and in complete ST/TT (absolute and mean values).

The results show that both hypotheses were confirmed in our study. The number of words processed in each paragraph in relation to the number of micro TUs and the time spent on the task reveals that subjects spent more time and made more effort per micro TU in the first paragraph. Thus, relatively to its length, the first paragraph took longer to translate. The number and types of micro TUs also indicate that processing effort was stronger in the first paragraph. Hypothesis one was, therefore, confirmed. As far as the conceptual/procedural distinction is concerned, the results indicate that AOIs 1 to 6 demanded more processing effort to be translated than AOIs 7 and 10 . There was a higher number of eye fixations in instances of PE-related problems. Fixation duration was also longer for PE. Processing effort also showed lower levels of complexity for micro TUs located in AOIs 7 and 10, pointing to a more localised type of cognitive processing. Therefore, hypothesis two was also confirmed.

\section{Concluding remarks}

The results of our study point to interesting observations concerning translation both as a process and as a product. Combining time spent on the task, seconds per word, and the number of micro TUs per word in each paragraph, we could show that there is a statistically significant difference in the way 
instances related to $\mathrm{CE}$ and $\mathrm{PE}$ are processed by professional translators. The joint use of key-logged and eye-tracking data to analyse processing effort yields insights into what type of processes are favoured when translators deal with either CE and PE. Whereas CE tends to favour a more localised type of processing effort, PE requires more complex and distributed operations which encompass longer stretches of text.

Overall, the results point to the validity of the proposed methodology for the selection of translation problems. The selected AOIs proved to be a valid choice to test some relevance-theoretic claims concerning the conceptual/procedural distinction in translation. The results point, almost always, to the allocation of longer stretches of time, and eventually more processing effort, in the processing of PE-related problems, as shown by the statistic tests: PE-related AOIs, on average, include more words and more micro TUs than the CE-related ones; PE-related words, on average, take longer to be processed; and PE-related micro TUs, on average, have more words.

Although the data set is relatively small to allow for robust generalizations, on the whole, the combined analysis of key logging and eye tracking highlights the explanatory power of a relevance-theoretic account of translation and provides a better understanding of the role of processing effort in translation. Other studies replicating our methodology and contrasting it in disparate language pairs would help us assess further the validity of our claims. We intend to do that by expanding the analysis presented herewith in similar studies to probe further into the consistency of a relevance-theoretic account of processing effort in translation.

\section{References}

Alves, Fábio. (2007) "Cognitive effort and contextual effect in translation: a relevance-theoretic approach." Journal of Translation Studies 10:1, pp. 18-35.

ALvES, Fábio \& Jose Luiz Gonçalves. (2003) "A Relevance Theory approach to the investigation of inferential processes in translation." In: Alves, Fábio (ed.) 2003. Triangulating Translation: Perspectives in Process-Oriented Research. Amsterdam: John Benjamins, pp. 3-24.

AlVES, Fábio \& Jose Luiz Gonçalves. (2013) "Investigating the conceptual-procedural distinction in the translation process: A relevance-theoretic analysis of micro and macro translation units." Target 25:1, pp. 107-124.

Alves, Fábio; Jose Luiz Gonçalves \& Karina Szpak. (2012) "Identifying instances of processing effort in translation through heat maps: An eye-tracking study using multiple input sources." In: Carl, Michael; Pushpak Bhattacharya \& Kamal Kumar Choudhary (eds.) 2012. Proceedings of the First Workshop on 
Eye-tracking and Natural Language Processing. 24th International Conference on Computational Linguistics. Mumbai: COLING 2012, pp. 5-20.

Alves, Fábio; Adriana Pagano; Stella Neumann; Erich Steiner \& Silvia HansenSchirra. (2010) "Translation units and grammatical shifts: towards an integration of product and process-based translation research." In: Shreve, Gregory \& Erik Angelone (eds.) 2010. Translation and Cognition. Amsterdam: John Benjamins, pp. 109-142.

Alves, Fábio; Adriana Pagano \& Igor A. L. da Silva. (2009) "A new window on translators' cognitive activity: Methodological issues in the combined use of eye-tracking, key-logging and retrospective protocols." In: Mees, Inger; Fábio Alves \& Susanne Göpferich (eds.) 2009. Methodology, Technology and Innovation in Translation Process Research. Copenhagen Studies in Language 37. Copenhagen: Samfundslitteratur, pp. 267-292.

Alves, Fábio \& Daniel Vale. (2009) "Probing the unit of translation in time: Aspects of the design and development of a web application for storing, annotating, and querying translation process data." Across Languages and Cultures 10:2, pp. 251-273.

Alves, Fábio \& Daniel Vale. (2011) "On drafting and revision in translation: A corpus-linguistics oriented analysis of translation process data. TC3 Translation: Corpora, Computation, and Cognition 1:1, pp. 105-122.

Blakemore, Diane. (2002) Relevance and Linguistic Meaning: The Semantics and Pragmatics of Discourse Markers. Cambridge: Cambridge University Press.

CARL, Michael \& Martin Kay. (2011) "Gazing and typing activities during translation: A comparative study of translation units of professional and student translators.” Meta: Journal des Traducteurs 56:4, pp. 952-975.

CARL, Michael \& Barbara Dragsted. (2012) "Inside the monitor model: Processes of default and challenged translation production." TC3 Translation: Computation, Corpora, Cognition 2:1, pp. 127-145.

FLOWER, Linda \& John R. Hayes. (1981) "A cognitive process theory of writing." College Composition and Communication 32:4, pp. 365-387.

HVElPlund, Kristian T. (2011) Allocation of Cognitive Resources in Translation: An Eye-tracking and Key-logging Study. Unpublished PhD Thesis. Copenhagen Business School. Electronic version available at: <http://openarchive.cbs.dk/ bitstream/handle/10398/8314/Kristian_T_Hvelplund_SL.pdf?sequence=1>

JAKOBSEN, Arnt L. \& Kristian T. Hvelplund Jensen. (2008) "Eye movement behaviour across four different types of reading tasks." In: Göpferich, Susanne; Arnt L. Jakobsen \& Inger M. Mees (eds.) 2008. Looking at Eyes: Eye-Tracking Studies of Reading and Translation Processing. Copenhagen Studies in Language 36. Copenhagen: Samfundslitteratur, pp. 103-124.

Just, Marcel A. and Patricia A. Carpenter. (1980) "A theory of reading: From eye fixations to comprehension.” Psychological Review 87:4, pp. 329-354. 
PAVlovi, Nataša $\&$ Kristian T. Hvelplund Jensen. (2009) "Eye tracking translation directionality." In: Pym, Anthony \& Alexander Perekrestenko (eds.) 2009. Translation Research Projects 2. Universitat Rovira i Virgili, Tarragona, pp. 101-119. Electronic version available at: < http://www.tobii.com/Global/ Analysis/Marketing/Research\%20Paper/linguistics\%20psychology/Eye\%20 tracking\%20translation\%20directionality.pdf>

RAYNER, Keith. (1998) "Eye movements in reading and information processing: 20 years of research." Psychological Bulletin 124:3, pp. 372-422.

RaYner, Keith A. \& Sara C. Sereno. (1994) "Eye movements in reading: Psycholinguistic studies." In: Gernsbacher, Morton A. (ed.) 1994. Handbook of Psycholinguistics. San Diego: Academic Press, pp. 57-81.

SCHILPEROORD, Joost. (1996) It's about time. Temporal Aspects of Cognitive Processes in Text Production. Utrecht: Rodopi.

SPERBER, Dan \& Deirdre Wilson. (1986/1995) Relevance: Communication and Cognition. $2^{\text {nd }}$ edition. Oxford: Blackwell.

WiLSON, Deirdre. (2011) "The conceptual-procedural distinction: past, present, and future." In: Escandell-Vidal, Victoria; Manuel Leonetti \& Aoife Ahern (eds.) 2011. Procedural Meaning: Problems and Perspectives. London: Emerald, pp. 3-28. 


\section{Appendix 1}

Heat maps for the eight subjects illustrating the distribution of effort in terms of fixation duration.

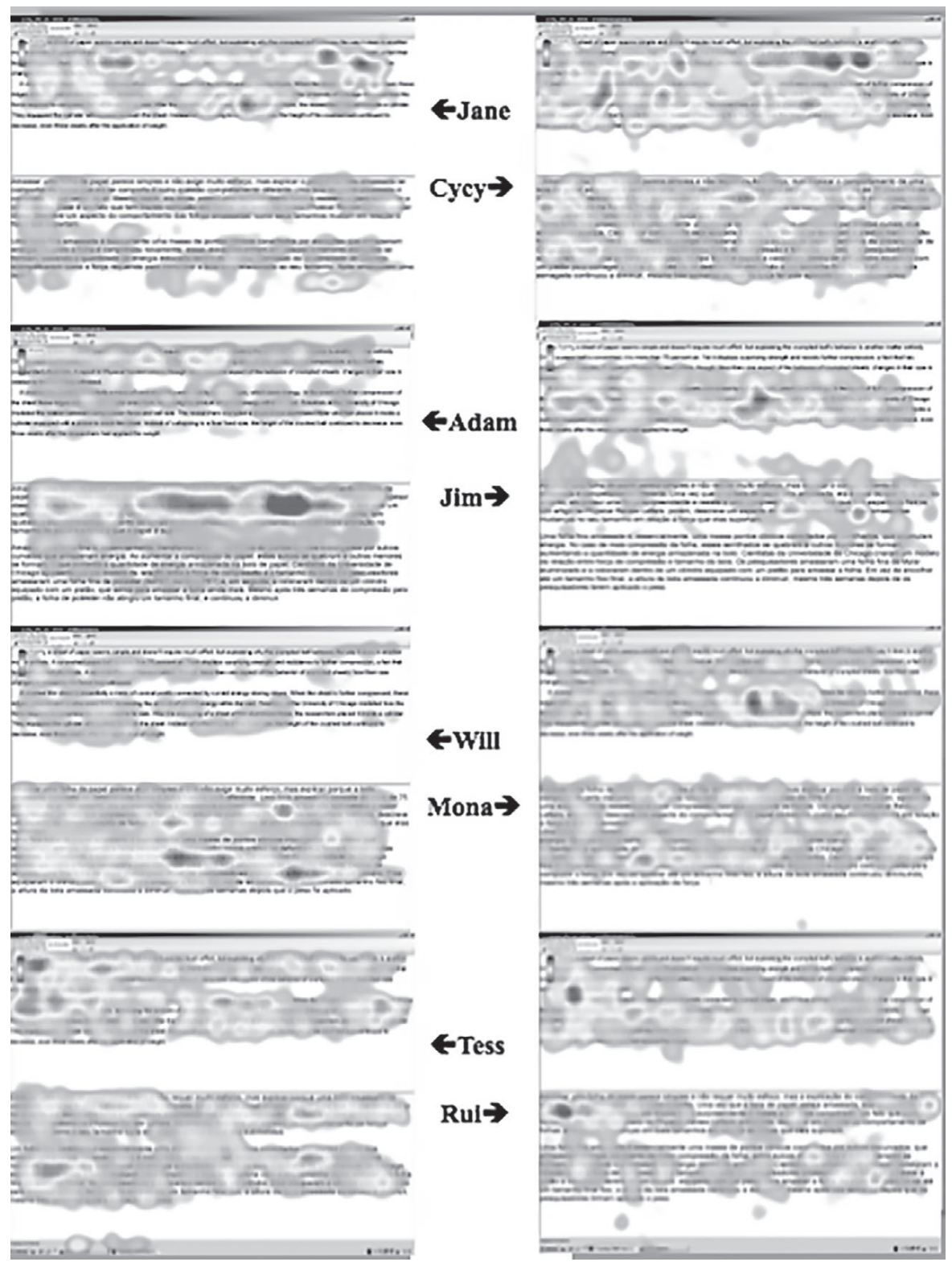




\section{Appendix 2}

Normality tests for Paragraphs 1 and 2 and for AOIs $1-6$ and AOIs 7-10.

NORMALITY TESTS

Paragraph 1

PROCESS DATA

Statistics: Asderoos:Datling

P.velue

\section{NORMALITY TESTS}

Pasagraph 2

\section{PROCESS DATA}

Statistics: Andersoo. Darling

P.velue
0.255917558

0,815878704

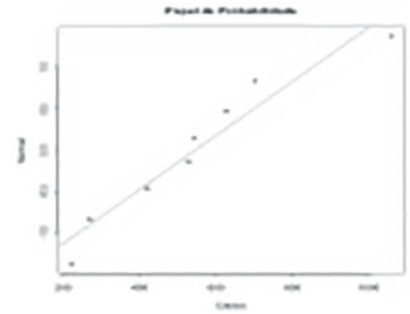

0.274150596

0,556991601

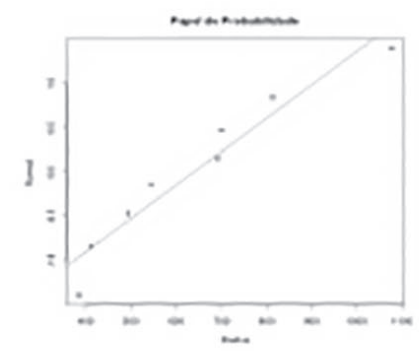

0,685971132

0,044326225
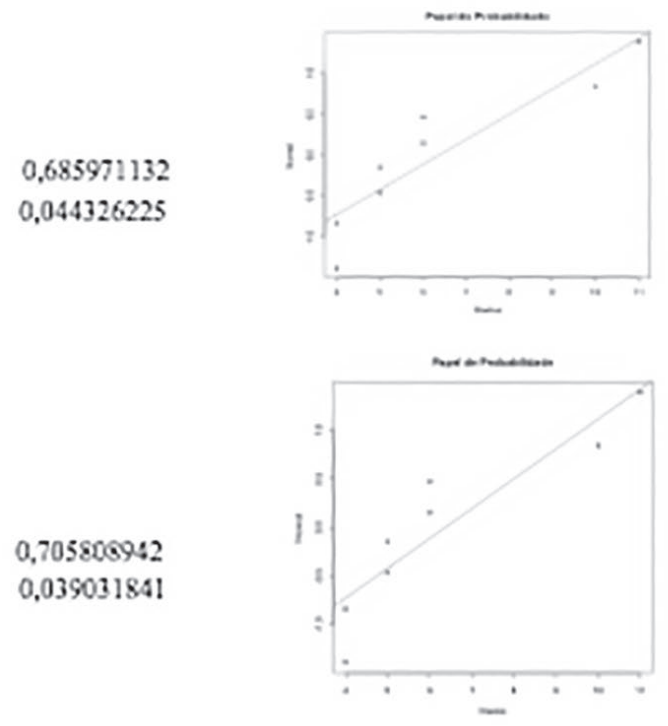

0,705800942

0,039031841
NORMALITY TESTS

NO1_7 and AO1_10

\section{PROCESS DATA}

Statistics: Aaderoo.Darling P.value 


\section{BIONOTES / NOTAS BIOGRÁFICAS}

Fábio Alves is Full Professor in Translation Studies at Universidade Federal de Minas Gerais (UFMG), Brazil, where he carries out empirical-experimental research at the Laboratory for Experimentation in Translation (LETRA). His research interests encompass expertise and expert knowledge in translation; cognitive approaches to translation; translation and technology; and human-machine interaction in translation. He has published extensively in journals such as Across Languages and Cultures, Meta and Target, as well as book chapters in Copenhagen Studies in Language (Samfundslitteratur), Continuum, Routledge and John Benjamins book series.

Fábio Alves es catedrático de Traductología en la Universidade Federal Minas Gerais (UFMG) de Brasil, donde efectúa investigaciones empírico-experimentales en traducción en el Laboratorio de Experimentación en Traducción (LETRA). Sus principales intereses de investigación incluyen la experticidad y el conocimiento experto en la traducción; los enfoques cognitivos de la traducción; traducción y tecnología; y la interacción entre traductores y sistemas automáticos de traducción. Entre otros, ha publicado artículos en Across Languages and Cultures, Meta y Target y capítulos de libros en las editoriales Samfundslitteratur (Copenhagen Studies in Language), Continuum, Routledge y John Benjamins.

José Luiz Gonçalves is Associate Professor in Translation Studies and English at Universidade Federal de Ouro Preto (UFOP), Brazil, and a Research Associate at the Laboratory of Experimentation in Translation (LETRA/UFMG), where he carries out empirical-experimental research in translation. His main research interests are expertise and expert knowledge in translation; cognitive approaches to translation; translation competence and translator's training/ education. He has published articles in Target, and book chapters in John Benjamins book series.

José Luiz Gonçalves es profesor asociado de Traductología e Inglés en la Universidade Federal de Ouro Preto (UFOP) de Brasil, e investigador colaborador en el Laboratorio de Experimentación en Traducción (LETRA/UFMG), donde lleva a cabo investigaciones empírico-experimentales en traducción. Sus principales intereses de investigación son la experticidad y el conocimiento experto en la traducción; los enfoques cognitivos de la traducción; la competencia traductora y la formación de traductores. Ha publicado artículos en Target y capítulos de libros en la editorial John Benjamins. 
Karina Sarto Szpak is currently a PhD student at Universidade Federal de Minas Gerais (UFMG), Brazil, where she works on empirical-experimental research in translation at the Laboratory for Experimentation in Translation (LETRA). Her main research interests encompass expert knowledge in translation; cognitive approaches to translation; and translation and technology. She has published a paper in the Proceedings of CoLing 2012.

Karina Sarto Szpak actualmente es estudiante de doctorado en la Universidad Federal de Minas Gerais (UFMG) de Brasil, donde realiza investigaciones empírico-experimentales en el Laboratorio de Experimentación en Traducción (LETRA). Sus principales intereses de investigación abarcan el conocimiento experto en la traducción; los enfoques cognitivos de la traducción; y la interacción entre traducción y tecnología. Ha publicado un artículo en las Actas de CoLing 2012. 